\title{
O espaço urbano na literatura árabe
}

\section{Paulo Daniel Farah}

Professor doutor da Faculdade de Filosofia,

Letras e Ciências Humanas da USP, no

Programa de Graduaçāo e Pós-graduação do

Departamento de Letras Orientais, e diretor do

Centro de Estudos Árabes da USP.

Resumo: A cidade evoluiu como uma das principais metáforas da modernidade e é um tema que aparece com freqüência na literatura árabe, especialmente na poesia. Em geral, ressaltam-se seus aspectos negativos. A cidade simboliza, na literatura árabe moderna, crueldade, desumanidade e inocência perdida. Com efeito, muitos autores árabes a retratam como um lugar de corrupção, opressāo, injustiça, ameaça, conspiraçōes políticas e sordidez social. A exceção é Jerusalém, ou, em árabe, Alquds (a cidade sagrada), importante centro religioso e político.

Palavras-chave: Literatura árabe; cultura urbana; modernidade; espaço; exílio
Abstract: The city is often represented as one of the most common metaphors in Arabic Literature, mainly in the field of modern poetry. Its negative aspects are generally emphasized, and the city represents cruelty, inhumanity and lost innocence. In fact, many Arab writers portray the city as a place of corruption, oppression, injustice, threat, political conspiracy and social sordidness. One exception is Jerusalem, or, in Arabic, Alquds (the holy city), an important religious and political centre.

Palabras-llave: Arabic literature; urban culture; modernity; space; exile 
A cidade evoluiu como uma das principais metáforas da modernidade - embora apareça na literatura clássica $^{1}$ - entre artistas e escritores realistas e modernistas durante os séculos XIX e XX: Honoré de Balzac e Guilhaume Apollinaire, na França; Charles Dickens e T. S. Eliot, na Inglaterra; James Joyce, na Irlanda; Adolfo Bioy Casares, na Argentina (em Diario de la guerra del cerdo); João Antônio Ferreira Filho, no Brasil (em Leão-de-chácara, por exemplo); Tokutomi Kenjiro, no Japão, e vários outros. Enquanto o romantismo buscava a arte verdadeira na unidade do homem com a natureza bela, mas selvagem, o realismo explorava a criação do homem e a destruição de si mesmo no encontro com a urbanidade.

$\mathrm{Na}$ sociedade religiosa, a cidade representa o centro sagrado do universo e é modelada de acordo com a criação divina: "O ato da criação foi um ato divino; quando o homem cria, ele repete o ato divino e formaliza a conexão através do ritual" (PIKE, 1981, p. 4). Para os modernistas, a cidade era o local do progresso tecnológico e da industrialização, assim como o ponto focal dos movimentos de vanguarda na arte (no caso da literatura, especialmente na poesia). A arte e a cidade eram meramente expressões diferentes do poder criativo do homem. A cidade era vista como "uma separação do mundo da natureza, a imposição da vontade do homem sobre uma ordem natural criada pela divindade" (PIKE, 1981, p. 5). A arte se tornou a imagem do homem. A cidade sagrada era uma imagem da cidade celeste, e a cidade moderna era uma imagem e também um cenário para a arte moderna.

Com freqüência, a cidade ideal da Utopia é contrastada com a sordidez da cidade terrestre. ${ }^{2} \mathrm{Na}$ Cidade de Deus, de Santo Agostinho, a tensão entre a cidade terrestre (baseada nos valores imediatos e mundanos) e a celeste (inspirada no amor a Deus e nos valores que Cristo pregou) revela o paradoxo da alienação civilizada.

Com a difusão da urbanização e as mudanças demográficas resultantes, a cidade se transforma num "campo urbano" descentralizado; o centro e a periferia não são mais evidentes (SHARPE, W. \& WALLOCK, L., 1987, p. 11-15).
${ }^{1}$ Ver SENNETT, R. (ed.). Classic Essays on the Culture of Cities. Englewood Cliffs, NJ: Prentice Hall, 1969; RUSSO, E. La cour et la ville dans la littérature classique Paris: PUF, 2002; CAWS. M. A. (ed.). City Images: Perspectives from Literature, Philosophy, and Film. Nova Iorque: Gordon and Breach, 1991; CRARY, J. Techniques of the Observer: On Vision and Modernity in the Nineteenth Century. Cambridge: MIT Press, 1990; LEHAN, R. The Gity in Literature: an intellectual and cultural history. Los Angeles: UCLA Press, 1998; CHAUVIN, D. (ed.). Paysages urbains, espace et mémoire. Ellug: Grenoble, 1999; SAQQAF, A. The Middle East City: Ancient Traditions Confront a Modern World. Nova Iorque: Paragon House, 1987.

${ }^{2}$ Ver SIMPSONHOUSLEY, P.; PRESTON, P. Writing the City: Eden, Babylon and the New Jerusalem, Routledge, 1994. 
Esse desenvolvimento tem um paralelo nas representações literárias da cidade. Na literatura romântica e realista, a paisagem física simbolizava principalmente os efeitos psicológicos e sociais da vida na cidade, claramente separados da vida no campo (SIMPSON-HOUSLEY, P. \& PRESTON, P., 1994, p. 2-3). A oposição entre a cidade como um local de corrupção e os valores naturais do campo constituem um motivo literário desde o período clássico.

A cidade cresce em importância a partir da industrialização. Nas obras modernistas, a vida moderna se igualava à vida urbana. A cidade podia ser vista como uma máquina ou um vórtice que engolia qualquer um que entrasse nela, como em Pegadas na areia, de Kenjiro, ou nas obras de Dickens (como David Copperfield ou Nicholas Nickleby). Esses romances têm um tema semelhante: um jovem ou uma jovem deixa o campo e vai para a cidade em busca de uma vida melhor. Embora o protagonista, depois de alguns obstáculos, encontre algumas vezes uma felicidade limitada, a vida na cidade é uma luta dura e sórdida pela existência e por valores morais.

A cidade se torna uma metáfora para a complexidade da vida moderna e o cenário para a expressão da alienação sentida pelo homem cercado por fronteiras constantemente em mutação: "De um certo modo, não existe mais uma cidade, existe apenas um homem andando por ela" (SIMPSON-HOUSLEY, P. ; PRESTON, P., 1994, p. 14). Uma semiunião entre o homem e a cidade se desenvolve, a qual se revela, ao mesmo tempo, fonte de desenvolvimento e de destruição. Os romances de Sherlock Holmes, de Arthur Conan Doyle, ilustram essa dicotomia. O brilhante detetive, que personifica os valores mais positivos do Iluminismo, é também uma vítima do lado sórdido da cidade através do uso de ópio e de sua tendência a sofrer de melancolia. $O$ caráter liminar da cidade é enfatizado. De acordo com Burton Pike, "a cidade parece expressar o sonho incansável de nossa cultura com seus conflitos internos e sua incapacidade de resolvê-los" (PIKE, 1981, p. 8). A cidade moderna é fonte de alienação e liberdade. A cidade moderna é o céu e o inferno, a corrupção e a perfeição (ibidem, 1981, p. 7-8). 
Malcolm Bradbury, citado por Sharpe e Wallock, analisou a representação da cultura urbana na arte:

O caos cultural criado pela cidade populosa, sempre crescente, uma torre de Babel contingente e poliglota, é representado no caos, contingência e pluralidade dos textos da produção moderna, no design e na forma da pintura modernista. (SHARPE, W. \& WALLOCK, L., 1987, p. 5)

De acordo com Inab Hassan, a essência da cidade reside numa "cumplicidade de linguagem, conhecimento e artifício" (HASSAN, I., 1981, p. 107).

\section{Literatura árabe}

A cidade é um tema proeminente na literatura árabe moderna, especialmente na poesia, mas, em geral, ressaltamse seus aspectos negativos. Na literatura árabe moderna, a cidade tende a funcionar principalmente como um objeto de menosprezo, rejeição e como um lugar de alienação. Ela não tem nome nem características distintivas. Ao citar a análise de Ihsan Abbas (ABBAS, I., 1978, p. 115), Bassam Frangieh afirma que a cidade é "um centro de corrupção, injustiça e conspiraç̃̃es políticas e é utilizada como um símbolo do mal, da opressão e da alienação. Ela também simboliza crueldade, desumanidade e inocência perdida. Dessa forma, os poetas rejeitam os males da sociedade contemporânea árabe quando rechaçam a cidade moderna" (FRANGIEH, B. K., 2000, p. 238).

Esse tema ganhou destaque desde que o poeta iraquiano Badr Chakir Assayyab lançou suas invectivas contra a cidade nos anos cinqüenta e descreveu suas ruas como "rolos de lama [que] corroem meu coração" (ASSAYYAB, B. C., 1960, p. 14), no poema "Jaykúr walmadína" ("Jaykur e a cidade"). Nessa obra, a cidade é associada com a corrupção social e política, assim como com a morte espiritual. A aldeia natal do poeta, Jaykur, ao contrário, representa a paz, a pureza e a bondade.

De fato, muitos poetas árabes viram na cidade um lugar de corrupção, ameaça e sordidez social. Seria uma terra 
${ }^{3}$ Cidade que, segundo o Alcorão, desrespeitou as instruções do profeta árabe Salih para pôr fim ao politeísmo e foi destruída por um terremoto.

${ }^{4}$ Tribo que, segundo o Alcorāo, desrespeitou as instruções do profeta árabe Hud para pôr fim ao politeismo e foi destruída por uma tempestade.

"Símbolos de vício e iniqüidade.

${ }^{6}$ Emile Habibi escreve sobre sua cidade natal (Haifa): "Nós, os árabes, tivemos uma cidade completamente desenvolvida em Haifa. Havia jornais, revistas e teatros. As pessoas lidavam com o trabalho e não se relacionavam com base em fundamentos religiosos ou comunitários. Onde eu vivia, eu não sentia diferença alguma entre uma garota cristã e uma mulçumana. Nós estávamos muito ocupados em gostarmos uns dos outros para fazer perguntas sobre religiäo. Nossas casas estavam abertas aos outros, nós estudávamos na mesma escola... Então eu cheguei à conclusão de que o estéril, um deserto, onde a alienação do poeta é completa. Esse tema foi tratado pela poesia modernista árabe com a experiência pessoal do poeta na cidade se fundindo com a experiência coletiva de procurar uma interpretação mais profunda para o embate entre o campo e a cidade. Essa oposição é também a oposição entre o bem e o mal, entre o lar e o exílio. Na poesia do iraquiano 'Abd Alwahhab Albayyati, a cidade reflete a situação política, simbolizando "os fluxos e os refluxos da vida política do Iraque" (FRANGIEH, B. K., 2000, p. 238).

Frangieh afirma que, "tal qual a situação árabe, a cidade está cheia de confusão e contradições, líderes corruptos e ladrões, forcas, prisões e incineradores" (ibidem, p. 237). A cidade representa uma situação social e política, não uma imagem da arte.

Há uma diferença clara no tratamento que os escritores árabes - sobretudo palestinos - dão às cidades palestinas e às cidades do exílio, locais de desabrigo e alienação (na mesma linha de tradição da cidade na literatura árabe em geral).

A cidade palestina tem um nome e uma identidade e não é retratada como Thamud ${ }^{3}, \mathrm{Aad}^{4}$, Sodoma e Gomorra ${ }^{5}$. Tampouco é uma fonte de ameaça. Ao contrário, ela é, muitas vezes, uma cidade-vítima, onde nenhuma alienação é vivenciada, uma cidade cercada e ocupada por usurpadores. O terror relacionado à cidade palestina é "externo", infligido a ela não pelo seu povo, como acontece com outras cidades árabes, mas por forças de agressões estrangeiras. Trata-se não apenas de uma cidade-vítima, mas, também, de um local de heroísmo, um reduto de resistência, um lar para a luta patriótica.

O poeta Samih Alqasim fala sobre a resistência na cidade palestina:

$\mathrm{Na}$ esquina da rua

Nos arredores da cidade

As crianças de longas histórias

Reúnem livros

Molduras de quadros e estacas

Para construir uma barricada

E bloquear o caminho da escuridão.

(ALQASIM, S., 1986, p. 119) 
Essa não é a cidade da derrota que assombra o restante da poesia árabe, mas a cidade da resistência mesmo depois de uma derrota.

Muitas cidades são mencionadas na literatura palestina. Jaffa e Haifa estão associadas a um importante passado histórico, cultural e político, que representa parte da experiência coletiva palestina. ${ }^{6}$ Nablus, Jenin e Gaza ${ }^{7}$ são cidades que desempenham uma função especial na luta contra a ocupação e por isso são louvadas.

\section{A cidade de Jerusalém}

Jerusalém ocupa um lugar de honra na literatura árabe, tanto na prosa como na poesia. Centro de boa parte da atividade religiosa, cultural e econômica dos palestinos, Jerusalém é também uma cidade isolada de seus arredores na Cisjordânia, pelas medidas forçadas de separação impostas pelo Exército israelense por vários anos, supostamente por razões de segurança, mas com óbvias implicações políticas para um objetivo declarado: a anexação de toda a cidade. ${ }^{8}$

Jerusalém, ou, em árabe, Alquds (o sagrado ou a cidade sagrada) ${ }^{9}$, é um centro de importância religiosa e política desde o início do Islã, como se evidencia no gênero literário conhecido como Fadâ'il Alquds, isto é, "Louvores de Jerusalém”. Este gênero único acompanhou a reconquista islâmica após a conquista de Jerusalém pelos cruzados em 1099. De fato, Jerusalém sempre preencheu um lugar especial em relação a outras cidades. Yitzhak Khuyutman a descreve como duas cidades, uma física, "a reunião concreta de facilidades materiais", a outra, uma Jerusalém construída na mente, "a vasta reunião de construções mentais que as pessoas mantêm acerca da cidade" (KhulUtman, Y., 1987, p. 178). Segundo Khuyutman, Jerusalém é o principal exemplo da dualidade entre a cidade real e a mítica, "tão emaranhada em seu mito que não está nem mesmo claro qual delas veio primeiro, a cidade real ou a mítica" (ibidem, p. 179).

Nas religiões abraâmicas, essas construções mentais golpe que desarraigou nossa sociedade da Palestina foi mais severo na sociedade árabe urbana do que na sociedade de aldeia porque a perda na cidade foi muito grande".

HABIBI, E. "Literature and Politics: A

Conversation with Emile Habibi". In: BOULLATA, I. (ed.) Mundus Arabicus 5. Cambridge: Dar Mahjar, 1992, p. 34-35.

${ }^{7}$ De fato, um lugar especial é reservado a Gaza já que esta foi a primeira cidade a se revoltar contra Israel durante a Intifada (levante palestino contra a ocupação) de 1987 a 1993.

${ }^{8}$ Israel conquistou a parte oriental da cidade em 1967 e a anexou em 1981. A ação nunca foi reconhecida pela ONU, mas Israel a considera sua capital eterna e indivisivel. Desde 1964, quando da assembléia que fundou a OLP

(Organização para a Libertação da Palestina), Jerusalém foi proclamada capital da Palestina. Essa posição do movimento de libertação nacional foi reiterada na proclamação da independência do Estado palestino no $19^{\circ}$ 
Conselho Nacional

Palestino, na Argélia, em 1988. Com base na resolução da ONU 242, os palestinos demandam a retirada de Israel de todos os territórios ocupados, incluindo Jerusalém.

${ }^{9} \mathrm{O}$ processo que busca validar as reivindicaçōes territoriais se expressa de forma acentuada através da denominação de Jerusalém. Em hebraico ("fundada pelo [deus] Shalem" ou derivado do aramaico “cidade da paz"), a cidade é nomeada Yerushalaym, que serve de modelo para a designação em diversas linguas - Jerzualém, em português - enquanto, em árabe, a forma seria Urchalim. Os povos de língua árabe, quase sem exceção, chamam Jerusalém de Alquds ou Bayt almaqdis que significa Casa Santa e que, aparentemente, relacionase ao termo Alquds axxarif, ou seja, A nobre Jerusalém.

${ }^{10}$ Os muçulmanos crêem em todos as profetas do judaísmo e do cristianismo, assim como em serus livros sagrados. "Cremos em Allah, naquilo que foi revelado a Abraão, Ismael, Istac, Jacó e às tribos, no que foi dado a Jesus, no que foi dado aos são o resultado da função religiosa de Jerusalém como o "local para a formação do mundo, a orientação espiritual, o sacrificio, a ressurreição, o Juízo Final e o símbolo da Redenção final para toda a humanidade" (KHUYUTMAN, Y., 1987, p. 181).

Para os judeus, Jerusalém foi onde Salomão construiu o primeiro templo, que se tornou um centro religioso e de peregrinação. Para os cristãos, é a cidade da paixão e da ressurreição de Jesus Cristo. Para os muçulmanos, é a qibla (orientação para a oração) original e lugar de onde Muhammad ascendeu aos céus. ${ }^{10}$

Na tradição judaica, Jerusalém é o "local de reunião entre a presença divina e o povo judaico" (KATZ, Y., 1994, p. 210). Os livros proféticos representam uma tradição mais pessimista. Os profetas reclamam da corrupção da cidade e predizem sua iminente destruição. Por causa da corrupção interna, a cidade é punida por Deus. Na época medieval, isso levou à interpretação de que mesmo a presença de Deus havia deixado Jerusalém e estava no galút (exílio) com o povo ${ }^{11}$. O retorno do povo do galút significaria o retorno da presença divina. Na Diáspora, a Eretz Israel, a Terra de Israel, adquiriu um caráter quase mitológico, e o desejo de voltar para ela é atestado nas obras de escritores medievais judeus. O retorno à Eretz Israel era o retorno à ordem cósmica, de acordo com Chaim Dimitrovsky: "O sagrado seria entronado num centro sagrado com um povo sagrado numa terra sagrada. Quando o centro está em ordem, o cosmo também está" (DIMITROVSKY, C., 1966, p. 67).

O retorno a Jerusalém seria a realização de uma esperança mantida no galút. A narrativa do Pessach (que comemora a fuga dos hebreus do Egito) expressa o desejo de estar no "próximo ano em Jerusalém".

Na literatura hebraica, a cidade é tanto perigo como bênção. Burton Pike indica uma tendência, na literatura ocidental moderna, de separar os dois aspectos da cidade, a destruição e a redenção, como duas representações em tempos diferentes. A cidade celeste está localizada num futuro distante, uma utopia e visão escatológica, enquanto a cidade da atualidade é aquela do inferno. En- 
contrar a Jerusalém física, relegar a cidade da corrupção e a cidade da perfeição a diferentes recortes temporais não é mais uma estratégia que funcione (PIKE, 1981, p. 8).

O caráter especial de Jerusalém como uma rede feita das camadas do passado está em oposição evidente às políticas israelenses depois de 1967, quando o país ocupou a parte oriental da cidade. Israel desempenha, há décadas, um esforço monumental para criar signos de uma cidade unificada de caráter essencialmente judaico (EFRAT, E., 1988, p. 11). Em retrospectiva, Jerusalém por volta de 1967 pode ser vista como "um tecido urbano emaranhado, o resultado de desejos históricos, religiosos, nacionalistas e políticos impressos numa extensão geográfica determinada cuja habilidade de abranger o novo sistema em implantação é duvidosa" (ibidem, p. 11). As complexidades em torno de Jerusalém se estendem além do conflito político do domínio sobre a cidade. Cada imagem da cidade física é filtrada através de imagens e metáforas preconcebidas. É

um símbolo condensado de todas as facetas da existência israelense que tanto os seculares quanto os religiosos consideram como santificadas, mas também como uma pedra de toque política de posições ideológicas contraditórias. Jerusalém serve, em todos esses contextos, como uma metonímia para toda a Terra de Israel, como um espelho refletindo a luta "externa" entre povos e religiões, e as controvérsias políticas internas, assim como uma metáfora para a entidade judaico-israelense como um todo. (BOAZ, A., 1997, p. 38)

Em crônicas antigas e obras geográficas, a característica mais importante de Jerusalém é sua significância espiritual. Jerusalém contém muitos lugares sagrados para o judaísmo, para o cristianismo e para o islamismo, como já se ressaltou.

Certa noite, segundo as fontes islâmicas, o profeta Muhammad foi levado de Meca a Jerusalém num animal celeste branco denominado Buráq (resplandecente). Na cidade sagrada, encontrou profetas como Abraão, Moisés e Jesus e orou com eles. Duas vasilhas foram postas diante profetas pelo senhor. Não temos preferência por nenhum deles" (Surata 2 , versículo 36). Por sua obediência à vontade divina, segundo o Alcorão, Jesus é considerado um exemplo a ser seguido. Através de vários versículos, o Alcorão também evoca a vida de Maria (Maryam), que dá nome a um dos capítulos corânicos.

${ }^{11}$ Entre outros, Micah Joseph Berdichevsky e Chayim Nahman Bialik escreveram sobre a vida judaica no exílio. 
12 Segundo os preceitos religiosos, os muçulmanos não devem beber vinho nem qualquer tipo de álcool.

${ }^{13}$ Os períodos posteriores à conquista da cidade pelo (segundo) califa 'Umar ibn-Alkhattáb (634-44) e, quatro séculos mais tarde, por Saladino (Salah Addin, 11381193), são descritos como modelos de tolerância. Com breves interrupções, os muçulmanos controlaram a cidade de 638 a 1099 e de 1187 a 1917. de Muhammad: uma com vinho e outra com leite. Ele tomou a que continha leite, mas ignorou a outra. ${ }^{12} \mathrm{Da}$ rocha que hoje se encontra dentro da Mesquita do Domo do Rochedo, em Jerusalém, ascendeu e atravessou os sete céus, revendo em todo seu esplendor os profetas e o arcanjo Gabriel. Após descender a Jerusalém, retornou a Meca pelo mesmo caminho e, quando chegou à Caaba, ainda era noite.

Jorge Luis Borges e Margarita Guerrero contam, em O Livro dos Seres Imaginários, que

uma das tradições islâmicas menciona que Buráq, ao deixar a Terra, derrubou uma jarra cheia d'água. O Profeta foi arrebatado até o sétimo céu e conversou em cada céu com os patriarcas e anjos que nele habitam e atravessou a Unidade e sentiu um frio que lhe gelou o coração quando a mão do Senhor lhe deu uma palmada no ombro. O tempo dos homens não é comensurável ao de Deus; em seu regresso, o Profeta levantou a jarra da qual ainda não se havia derramado uma só gota. (BORGES, J. L.; GUERRERO, M., 1985, p. 70-71)

O místico Abu-Bakr Muhammad ibn-'Arabi (1165-1240) descreveu Jerusalém como uma “estação do sagrado e da pureza numa geografia espiritual em que Meca é o coração perfeito que contém a verdade e Medina é o local onde o adepto espiritual busca a habilidade de ver Deus em tudo" (SCHLEIFER, A., 1987, p. 167). A jornada noturna do profeta forneceu inspiração para o misticismo islâmico. Muitos místicos foram atraídos para Jerusalém e alguns foram enterrados ali.

Jerusalém é também "o exemplo mais perfeitamente preservado de uma cidade medieval islâmica", de acordo com Abdullah Schleifer (SCHLEIFER, A., 1987, p. 163). Além disso, Jerusalém é vista como um símbolo da cidade islâmica pluralista. ${ }^{13}$

Muitos poemas retratam Jerusalém e seus sítios sagrados, incluindo a mesquita de Al'Aqsa (a terceira mais sagrada no islamismo), Buráq (animal celeste no qual Muhammad realizou sua viagem aos céus; é também o nome 
que os muçulmanos atribuem à parte ocidental do muro em Jerusalém, conhecido também como Muro Ocidental ou Muro das Lamentações), o Domo do Rochedo (mesquita que fica próxima à mesquita de Al'Aqsa) e a Igreja do Santo Sepulcro (local da crucificação e da ressurreição de Cristo). Alguns poetas invocavam os símbolos religiosos da cidade para inspirar a resistência aos "novos cruzados" (como eram chamados com freqüência) britânicos e sionistas.

Muitos poetas eram cristãos e, numa dimensão por vezes maior do que a de seus compatriotas muçulmanos, tomaram o cuidado de adotar símbolos que agradassem aos adeptos de ambas as religiões. Líderes políticos palestinos também se esforçaram para apresentar uma frente unida às autoridades britânicas e aos sionistas.

Wadi' Albustani, um cristão libanês que chegou à Palestina como oficial da Administração do Mandato Britânico, rapidamente se tornou uma figura importante do movimento nacionalista e um de seus poetas mais prolíficos. Albustani falava sobre Jerusalém como uma cidade sagrada para o cristianismo e para o islamismo e invocava a mesquita de Al'Aqsa, a Igreja do Santo Sepulcro, o Domo do Rochedo e o Monte das Oliveiras como locais religiosos nacionais ameaçados pelos estrangeiros (BUSTANI, W., 1946, p. 120, 186, 193-194).

Conforme a luta contra as forças estrangeiras se intensificava, os poetas empregavam a técnica tradicional de se referir às vitórias árabes do passado para inspirar o público. Uma delas foi a Batalha de Hittin, na Galiléia, na qual Saladino derrotou o Exército dos cruzados e abriu caminho para a reconquista muçulmana de Jerusalém. Hittin se tornou um símbolo poderoso da resistência árabe-palestina e é mencionada em vários poemas, incluindo "Hittin", que integra a antologia de Ibrahim Tuqan (TUQAN, I., 1966, p. 50-54).

Além disso, mencionam-se outras terras para fortalecer a resistência. Com o espectro da derrota assombrando, muitos poetas evocavam a imagem da Espanha muçulmana, um período e um lugar dourados na história árabe até que seus habitantes muçulmanos fossem forçados ao exílio (ALKAYYALI, A., 1975. p. 119). 
${ }^{14}$ Darwich nasceu em 1942 na aldeia de Birwa, nos arredores de Akka (Acre), perto da costa mediterrânea da Palestina Seu primeiro livro de poesia, 'Assáfir bilá 'ajniha (Pássaros sem asas), foi publicado em 1960. Um de seus poemas mais conhecidos, "Bitáqat hawiyya" (Carteira de Identidade), integra a obra 'Awráq azzaytún (Folhas de oliveira, seu segundo livro, publicado em 1964), na qual desenvolve uma expressão poderosa e direta de sua identidade.

${ }^{15}$ Biblia de Jerusalém. São Paulo: Paulus, 1995, Lamentações, Primeira lamentação, versículo 8 .

${ }^{16}$ Ibidem, versículo 9.

!17 Ibidem, versículo 11 .

\section{Jerusalém na obra de Darwich}

Na obra do poeta Mahmud Darwich ${ }^{14}$, a fragmentação da identidade de Jerusalém se reflete no intercâmbio entre duas designações da cidade: Alquds, o nome árabe, e Urchalim (ou 'Urxálím), uma transcrição árabe de Jerusalém na forma hebraica (Yerushalaym). Esses dois nomes indicam diferentes tradições de Jerusalém na poesia.

Em Mazámír (Salmos), uma série de poemas dedicados a Jerusalém, a cidade é transformada de Urchalinn em Alquds. Urchalim é a cidade deserta e amaldiçoada dos livros proféticos do Antigo Testamento.

Nas Lamentações, descreve-se o estado miserável de Jerusalém:

\section{Jerusalém pecou gravemente}

e tornou-se impura;os que antes a honravam, desprezam-na, vendo-lhe a nudez,e ela, entre gemidos, volta as costas. ${ }^{15}$

Sião personificada toma a palavra no versículo $9 \mathrm{e}$ no versículo 11 para queixar-se:

Leva sua impureza nas vestes sem pensar no futuro.

tão baixo caíste!não há quem a console.

"Vê, Senhor, minha miséria

e o triunfo de meu inimigo." 16

Todo o seu povo, entre gemidos, procura pão;

deram seus tesouros para comer, para reencontrar a vida."Vê, Iahweh, olha como me tornei desprezível!" 17

Em algumas versões, as Lamentações têm uma introdução: "Aconteceu que, depois da redução de Israel ao cativeiro e de Jerusalém a deserto, o profeta Jeremias sentou-se chorando; ele proferiu esta lamentação sobre Jerusalém e disse...". ${ }^{18}$

Em Mazámír, inicialmente Darwich se refere à cidade como Urchalim: 
A aridez se espalhou por dentro por muitas razões

Quem vai retornar o fluxo das estações

Quem vai mudar a ordem do calendário

Quem vai me ensinar as elegias de Jeremias

nos caminhos de Urchalim que o Senhor amaldiçoou

Para que eu descreva pela primeira vez

a história do meu nascimento

Quem? (DARWICH, M., 1972, p. 15)

A denominação se modifica na última parte de Mazámír: Quando há esperança, o nome da cidade também muda. Quando as crianças da Babilônia são encorajadas a voltar e se libertarem das correntes, não se trata mais de um retorno a Urchalim, mas à Alquds árabe.

${ }^{18}$ Citado em Bíblia de Jerusalém. São Paulo: Paulus, 1995, p. 1.579.

Nós cantamos Alquds

Ó, crianças de Babel

Descendentes do grilhão

Logo voltarão a Alquds

Logo crescerão

Logo colherão o trigo na memória do passado

Logo as lágrimas serão espigas ${ }^{19}$ e grão.

Logo voltarão a Alquds

Logo crescerão

Logo

Logo

Logo...

Aleluia

Aleluia! (ibidem, p. 38)

Em "Madíh lizzill al'álí" ("Louvor à sombra que se ergue"), Jerusalém aparece como Urchalim num contexto de destruição e morte. A deportação iminente no tempo de Isaías se torna um evento paradigmático para a experiência palestina.

Dos Salmos forjam armas?

Uma vítima

matou

sua vítima

$\mathrm{E}$ eu tive sua identidade

Convoco Isaías: vá-te dos livros antigos 
${ }^{20}$ Bíblia de Jerusalém, Isaías, capítulo 2 , versículos 3 e 4 . como eles partiram

As alamedas de Jerusalém

penduram a carne palestina nas escadas

do Antigo Testamento

e rogam que a vítima não mude sua pele

Isaías... não lamente

Escarneça da cidade para eu amá-lo duplamente

proclamar a esperança

perdoar ao judeu jovem e suas lágrimas

Os papéis da peça sangrenta se misturaram

Não há juiz afora os mortos

A palma da mão do assassino se fundiu aos ditos do martírio

$\mathrm{E}$ os mortos adentraram o reino de seus assassinos.

(DARWICH, M., 1966, p. 53)

O poema faz referência à profecia escatológica em Isaías sobre o tempo em que as armas serão destruídas e todas as pessoas serão reunidas em Sião:

Muitos povos virão, dizendo:

"Vinde, subamos ao monte de Iahweh,

à casa do Deus de Jacó,

para que ele nos instrua a respeito dos seus caminhos

e assim andemos nas suas veredas."

Com efeito, de Sião sairá a Lei,

E de Jerusalém, a palavra de Iahweh.

Ele julgará as nações,

Ele corrigirá a muitos povos,

Estes quebrarão as suas espadas, transformando-as em relhas,

$\mathrm{E}$ as suas lanças, a fim de fazerem podadeiras.

Uma nação não levantará a espada contra a outra,

E nem se aprenderá mais a fazer guerra. ${ }^{20}$

No poema de Darwich, a realização dessa profecia ainda é aguardada, e Isaías é visto como um profeta que deve escarnecer de Jerusalém. Não só as armas não foram destruídas como elas passaram a ser feitas dos Salmos ("Dos Salmos forjam armas?"). O Antigo Testamento se tornou uma forca para a carne palestina. $O$ desejo judaico pelo reino se torna o desejo palestino por presença. 


\section{A Babilônia}

Na obra de Darwich, o exílio e o aprisionamento representam diferentes aspectos da experiência do sofrimento. A ligação entre as metáforas para a prisão e para o exílio também é encontrada em relatos bíblicos relacionados ao exílio babilônico.

Na poesia inicial de Darwich, o exílio judaico na Babilônia (em 597 a.c.) se tornou, como Jamal Ahmad Arrifa i observa, uma metáfora para o exílio palestino:

O poeta Mahmud Darwich descreve o exílio palestino no século XX como uma Babilônia para sugerir que a provação do exílio palestino não difere muito daquela da diáspora judaica. Ao ler seus versos, descobrimos que o poeta usa a palavra salásil (correntes, grilhões) não para rimar com Bábil (Babilônia), mas para sugerir que ficar na Babilônia, sinônimo de exílio, irá fazer dos agrilhoados palestinos prisioneiros dos caldeus, incapazes de traçar seu destino e futuro. (ARRIFA'I, J. A., 1994, p. 45)

Em "Waxm al'abíd” ("A marca do escravo"), a Babilônia exemplifica, ao lado de Roma, os impérios tirânicos que marcaram a humanidade e passaram. O retorno dos prisioneiros da Babilônia inspira esperança, apesar das marcas indeléveis.

A Babilônia em volta do pescoço A marca dos prisioneiros que voltaram As roupas dos tiranos já mudaram Aquele que vive depois da morte Se você crer... não morrerá Nós morremos e vivemos e a estrada é uma! (DARWICH, M., 1966, p. 110-111)

O narrador se identifica com a esperança associada ao retorno dos prisioneiros da Babilônia. Assim como eles retornaram, os exilados da Palestina irão voltar para casa. A Babilônia é a metáfora do exílio forçado e também a de um exílio que irá terminar.

Em "Salát akhíra" ("Última oração"), Nero, o faraó e a Babilônia representam os impérios de Roma, do Egito e da Babilônia, impérios cujo domínio passou: 
Meu país! Criança

Nos pés de sua mãe morrem grilhões

E vêm novos entraves...

Quando então virá o brinde

Nem que apenas no poema?

Morreu o faraó

Nero morreu

E a vida retornou

A todos os prisioneiros da Babilônia!

Quando então virá o brinde

Nem que apenas nas canções? (ibidem, p. 161)

O faraó e Nero morreram e os prisioneiros da Babilônia ganharam uma nova vida, o que indica esperança no futuro. O poema guarda semelhança com os textos proféticos da Bíblia, nos quais se afirma que a Babilônia irá cair. Mas, na poesia de Darwich, muitas vezes a nova vida e a liberdade só podem ser obtidas "nas canções" ou "na poesia".

Em Mazámír (Salmos), a Babilônia marca o exilado profundamente: "A Babilônia vive nas rugas do meu rosto / Onde quer que eu vá..." (DARWICH, M., 1972, p. 35).

O exílio na Babilônia está inscrito no rosto do exilado. Ainda assim, há esperança de retorno. "Eu espero aqueles que retornam / Eles conhecem os tempos da minha morte e vêm" (ibidem, p. 22). Os prisioneiros da Babilônia não são apenas imagens poderosas da esperança do retorno de um exílio terreno, mas também da esperança escatológica de retornar à vida.

Darwich trata pela primeira vez do tema da cidade em "Da"wa littadhkár" ("Chamamento à lembrança"). Nesse poema, a cidade é perdida com a partida de seus habitantes, "as tristes aves migratórias". A ligação está em perigo por causa da migração, e pode-se observar que o pior pecado é o esquecimento.

As tristes aves migratórias esqueceram sua face Como ela se perdeu se tu eras

Minha chave para o coração da cidade? (ibidem, p. 135)

A Palestina é retratada como um país predominantemente rural na obra de Darwich e de outros autores 
árabes. Especialmente em sua poesia inicial, as cidades quase não são representadas. Apenas alguns lugares nomeados, como Haifa e Akka (Acre), têm o mesmo conteúdo emocional do país rural, mas a dicotomia tradicional entre o rural e o urbano não é tão importante. A oposição é definida pelo exílio versus o lar. As cidades do lar pertencem ao mesmo plano do país rural, e o impacto do porto e do mar como imagens do início de uma viagem coloca as cidades costeiras no plano do exílio (como se observa, por exemplo, em 'Áxiq min Filastín (Enamorado da Palestina), de 1966. 


\section{Referências}

ABBAS, I. Axxír al'arabiy (A poesia árabe). Kuait: Almajlis alwataní liththaqáfa walfunún waladab, 1978.

ALKAYYALI, A. Axxi'r alfilastininiy fi nakbat Filastin (Poesia palestina sobre a catástrofe da Palestina). Beirute: almanxúrát al'arabiyya, 1975.

ALQASIM, S. Xakhs ghayr marghúb fíhi (Persona non grata). Beirute: Dár alkalima, 1986.

ARENDT, H. Entre o passado e o futuro. 4. ed. São Paulo: Perspectiva, 1997.

ARRIFA'I, J. A. Athar aththaqáfa al'ibiryya fixxi'r alfilastini almu'ásir (Influência da cultura hebraica na poesia palestina contemporânea). Cairo: Dár alhilál, 1994.

ASSAYYAB, B. C. 'Unxudat almatar (Hino da chuva). [s.l.s.n.], 1960.

BADIE, B. La fin des territoires. Paris: Fayard, 1995.

BENARAB, A. Les voix de l'exil. Paris: L'Harmattan, 1994. BHABHA, H. K. O local da cultura. Tradução Myriam Ávila, Eliana Lourenço de Lima Reis e Gláucia Renate Gonçalves. Belo Horizonte: UFMG, 1998.

BOAZ, A. "On the Political Significance of Amichai's poetry" em ABRAMSON, G. (ed.) The experienced soul: studies in Amichai. Boulder, CO: Westview Press, 1997.

BORGES, J. L. \& GUERRERO, M. O Livro dos Seres Imaginários. Tradução de Carmen Vera Cirne Lima. Porto Alegre/Rio de Janeiro: Globo, 1985.

BOURDIEU, P. O poder simbólico. Lisboa/Rio de Janeiro: Bertrand Brasil / Difel, 1989.

BUSTANI, W. Diwán alfilasttniyyát (Antologia palestina). [s.l.:s.n.], 1946.

CAWS. M. A. (ed.). City Images: Perspectives from Literature, Philosophy, and Film. Nova Iorque: Gordon and Breach, 1991. CHAUVIN, D. (ed.). Paysages urbains, espace et mémoire. Ellug: Grenoble, 1999.

CLAVAL, P. La géographie culturelle. Paris: Nathan, 1995. CRARY, J. Techniques of the Observer: On Vision and 
Modernity in the Nineteenth Century. Cambridge: MIT Press, 1990.

DARWICH, M. 'Axiq min Filastín (Enamorado da Palestina). Amã: Dár axxurúq, 1966.

DARWICH, M. Uhibbuki 'aw lá uhibbuki(Eu te amo ou não te amo). Beirute: Dár al'awda, 1972.

DIMITROVSKY, C. "Zion in Medieval Literature: Poetry" em HALKIN, A. Zion in Jewish Literature. Lanham: University Press of America, 1966.

EFRAT, E. Geography and politics in Israel since 1967. Londres: Frank Cass Publishers, 1988.

FRANGIEH, B. K. "Modern Arabic poetry: vision and reality" . In: ABDEL-MALEK, K. ; HALALQ W.

Tradition modernity, and postmodernity in Arabic literature: essays in honor of professor Issa J. Boullata. Leiden: Bril, 2000.

GIDDENS, A. As conseqüências da modernidade. Tradução Fernando Luís Machado e Maria Manuela Rocha. São Paulo: UNESP, 1991.

HABIBI, E. "Literature and Politics: A Conversation with Emile Habibi" em BOUllatA, I. (ed.) Mundus Arabicus 5. Cambridge: Dar Mahjar, 1992.

HALALQ W. (ed.) Tradition, modernity, and postmodernity in Arabic literature: essays in honor of professor lssa J. Boullata. Leiden: Brill, 2000.

HASSAN, I. "Cities of Mind, Urban Words" . In: JAYE, M. C. \& WATTS, A. C. Literature \& the Urban Experience: Essays on the City and Literature. New Brunswick: Rutgers University Press, 1981.

HOUSLEY, P. ; PRESTON, P. Writing the City: Eden, Babylon and the New Jerusalem, Routledge, 1994.

KATZ, Y. Jerusalem in S. Y. Agnon's Yesterday before Yesterday. In: SIMPSON-HOUSLEY, P. \& PRESTON, P. Writing the City: Eden, Babylon and the New Jerusalem. Routledge, 1994.

KHUYUTMAN, Y. "Zion and the Two Jerusalems" em 
SAQQAF, A. The Middle East City: Ancient Traditions Confront a Modern World. Nova Iorque: Paragon House, 1987.

LEFEBVRE, H. La production de l'espace. Paris: Fayard, 1984.

LEHAN, R. The City in Literature: an intellectual and cultural history. Los Angeles: UCLA Press, 1998.

PIKE, B. The image of the city in modern literature. Princeton:

Princeton University Press, 1981.

RUSHDIE, S. Imaginary homelands. Londres: Granta Books, 1992.

RUSSO, E. La cour et la ville dans la littérature classique. Paris:

PUF, 2002.

SACK, R. Human Tenritoriality. Cambridge: Cambridge University Press, 1986.

SAQQAF, A. The Middle East City: Ancient Traditions Confront a Modern World. Nova Iorque: Paragon House, 1987.

SCHLEIFER, A. "Islamic Jerusalem as Archetype of a Harmonious Urban Environment" . In: SAQQAF, A. The Middle East City: Ancient Traditions Confront a Modern World. Nova Iorque: Paragon House, 1987.

SENNETT, R. (ed.). Classic Essays on the Culture of Cities. Englewood Cliffs, NJ: Prentice Hall, 1969.

SHARPE, W. ; WALLOCK, L. (ed.) Visions of the Modern City. Essays in History, Art, and Literature. Baltimore: Johns Hopkins University Press, 1987.

SIMPSON-HOUSLEY, P. \& PRESTON, P. Writing the City: Eden, Babylon and the New Jerusalem. Routledge, 1994. SUBIRATS, E. Memoria y exílio. Buenos Aires: Lozada Editoria, 2003.

TUQAN, I. Diwán Ibrahím Tuqqn (Antologia de Ibrahim Tuqan). Beirute: Dár al'adab, 1966.

WEIPPERT, H. Palästina in vorhellenistischer Zeit.

München: C.H. Beck'sche Verlags-buchhandlung, 1988. 